\title{
Laparoscopy Assisted Distal Gastrectomy for Cancer at a Tertiary Center in Egypt. Is It Safe and Feasible?
}

\author{
Anwar Tawfik Amin*, Ahmed A. S. Salem, Hussein Fakhry, Murad A. Jabir \\ Surgical Oncology Department, South Egypt Cancer Institute, Assiut University, Assiut, Egypt \\ Email: *anwar71@oita-u.ac.jp
}

How to cite this paper: Amin, A.T., Salem, A.A.S., Fakhry, H. and Jabir, M.A. (2017) Laparoscopy Assisted Distal Gastrectomy for Cancer at a Tertiary Center in Egypt. Is It Safe and Feasible? Journal of Cancer Therapy, 8, 1179-1186. https://doi.org/10.4236/jct.2017.813101

Received: November 12, 2017

Accepted: December 11, 2017

Published: December 14, 2017

Copyright (c) 2017 by authors and Scientific Research Publishing Inc. This work is licensed under the Creative Commons Attribution International License (CC BY 4.0).

http://creativecommons.org/licenses/by/4.0/

\section{c) (i) Open Access}

\begin{abstract}
Background: Laparoscopic radical gastrectomy for cancer has significant short- and long-term advantages. The feasibility and safety of laparoscopicdistal gastrectomy for cancer (LADG) is unclear in low to middle income countries as resources are limited. Therefore, the aim of this study was to evaluate the safety and feasibility of (LADG) in low to middle income countries; Egypt as an example. Methods: Thirty four Patients with stage I-II cancer at the pylorus and antrum have been enrolled for LADG between 2012 and 2015 with the reuse of single use vascular sealing device has been evaluated. Results: Finally 27 patients had been included in the study and successful LADG has been done for all selected cases. The average operative time was $151 \pm 10$ minutes. The average estimated blood loss was $73.3 \pm 13 \mathrm{ml}$. No intra-operative complications have been recorded. The average time for postoperative patient ambulation was 9 hours $(S D \pm 1.8)$ and for oral fluid intake was $3.5 \mathrm{SD} \pm 1$ days. The average duration of the hospital stay was $9.3 \pm 1.2$ days. The average number of retrieved lymph nodes was $21.7 \pm 3.8$ days. All the cases had free surgical margin. The median number of reuse of the vascular sealing device was 3.8 times ( 3 - 5 times). Conclusion: Laparoscopic distal gastrectomy for cancer could be safe and feasible in developing countries and give similar results for that of developed countries. Safe reuse of single use expensive parts of some instruments for laparoscopy could help in utilization of these advanced surgeries in low to middle income countries. Long term follow up as well as comparative studies with open surgery are required.
\end{abstract}

\section{Keywords}

Gastrectomy, LADG, Laparoscopy, Disposable Instruments 


\section{Introduction}

The first report of laparoscopy assisted distal gastrectomy (LADG) for early gastric cancer was 1994 by S. Kitano et al. and since then, the procedure has progressively gained maturity in its techniques and indications [1] [2] [3] [4]. Recently, reports have shown the feasibility of the procedure for locally advanced gastric cancer [5]. Significant short- and long-term benefits compared with the open approach has been obtained by this technique [1] [2] [3] [4] [5]. The quality of life of the patients following gastric cancer surgery could be improved by these developments.

Despite the evidences from multiple retrospective and some prospective randomized trials regarding the benefits of laparoscopic radical distal gastrectomy for cancer; laparoscopic gastrectomy has low adoption rate. Furthermore, the implementation of laparoscopic techniques in low and middle income countries has been challenging, because of the equipment high cost and the shortage of expertise [6]. However, many laparoscopic procedures, including cholecystectomy, appendectomy, splenectomy and hysterectomy have been successfully performed in low and middle income countries [7] [8] [9].

A survey was conducted in Ghana a limited resources country among patients visiting specialist clinics. The survey found that the patients lacking knowledge about laparoscopy and its benefits. However, once educated about its advantages, most people prefer laparoscopic approach even if they needed to pay extra money for it [10]. International training programs for surgeons from low and middle income counties aiming at integration of laparoscopy as a part of surgical practice in their countries are very important. A recent study showed that, incorporation of low-cost laparoscopic skills programs in low income countries is potentially feasible. Such approach could provide residents from countries with limited resources much-needed opportunities and training and could be a vital part in the growing surgical residency program in resource limited regions [11].

Providing oncological outcomes similar to those obtained in a developed setting will further encourage and support the steady growth of laparoscopy for cancer in low income countries [12] [13] [14] [15] [16]. Currently, there are almost no data referring to the oncologic feasibility and the surgical safety of laparoscopic distal gastrectomy for cancer in the situation of limited equipment in developing countries.

Therefore, this study aims at the evaluation of the safety and feasibility of laparoscopic distal gastrectomy for adenocarcinoma that could be performed under a limited resource setting in a tertiary hospital in Egypt as an example of the low to middle income countries. Reuse of single use vascular sealing device for distal gastrectomy will be evaluated.

\section{Patients and Methods}

This is a feasibility and safety non randomized phase I clinical study. The research was performed at South Egypt Cancer Institute, Assiut University, Egypt. 
Thirty-four patients with pyloric and antral stage I-II cancer have been enrolled in this study for laparoscopy assisted distal gastrectomy in the period of May 2012 to November 2015. The diagnosis of gastric cancer was confirmed with gastroscopy and biopsy.

Abdominal computed tomography (CT) has been done for all the cases. The following findings have been used to include the patients into the study: histologically proven adenocarcinoma, with clinical stage T1 to T2 at the pylorus or antrum, absence of serosal and outside-gastric invasion as well as no distant metastasis could be detected by imaging tools or laparoscopic exploration. Patients with peritoneal metastasis, hepatic metastasis, T3 or more tumor as well as distant metastasis have been excluded. The ethical committee at South Egypt Cancer Institute has approved this study. After discussion with the patients on the benefits and risks of the surgery the surgical approach was decided after the patient consent.

The 3rd English edition of the Japanese classification of gastric carcinoma has been used for the lymph nodes classification around the stomach [17]. The 7th edition of the UICC tumor, node, and metastasis (TNM) classification has been used for staging [18]. Cancer free surgical margin (R0) curative attempts with Perigastric and left gastric lymphadenectomy (D1 plus) lymphadenectomy was tried in all patients according to the guidelines of the Japanese gastric cancers treatment [19].

The need for premature performing of laparotomy for gastric mobilization and/or bleeding control was defined as conversion. The operative related mortality was defined as death occurred at the same hospital stay or within 30 days after surgery. Operative morbidities were complications that result in hospital stay prolongation or the need for additional procedures [20].

\section{Surgical Procedure}

For economic causes, we usually use reusable laparoscopic instruments. For disposable instruments, we reuse it several times after proper sterilization, provided that it works efficiently. The only disposable laparoscopic instrument that has been used for several times in this study was the vascular sealing device. All other surgical instruments used in this study were reusable.

Laparoscopy assisted distal gastrectomy with "D1 plus" peri-gastric lymphadenectomy was done according to the principals of the Japanese Gastric Cancer Association for the gastric cancer management [17] [19]. All the procedures were performed similar to our previously described technique with slight modification by adding a fourth port at the right pre-axillary line $2-3 \mathrm{~cm}$ below costal margin to be used for liver retraction [21].

First of all, the stomach and the abdominal cavity were laparoscopically inspected to exclude adjacent organ involvement and peritoneal metastasis.

After the gastric and lymph nodes dissection has been completed, the umbilical port site was vertically extended $4-5 \mathrm{~cm}$ for stomach extraction and recon- 
struction. The proximal transection site of the stomach was decided according to the tumor site. The hand-sewn method was used for performing Billroth-I, Billroth-II or Roux-en-Y anastomosis extra-corporeally.

\section{Collection and Statistical Analysis of Data}

The patient's demographic data, associated morbidities, tumor location, details of the surgery, operative outcomes, as well as follow up data were prospectively gathered and put into a data base. Student's-t test was used to compare the median reuse of vascular sealing device in gastrectomy and colectomy.

\section{Results}

Thirty-four patients with gastric cancer at the antrum and pylorus that have been proven pathologically with clinical stages T1-T2 have been selected for laparoscopy assisted distal gastrectomy (LADG). After laparoscopic exploration, 7 patients $(7 / 34=20 \%)$ were excluded from the study because of tumor invasion into the serosa or neighbor organs in 3 case, metastasis to the liver and invasion to serosa in 2 cases and peritoneal metastasis in 2 cases. The other 27 cases have been selected for the study, Table 1 . LADG procedures were successfully performed.

The operative meantime was $151 \pm 10$ minutes. The estimated blood loss mean was $73.3 \pm 13 \mathrm{ml}$. The use of additional port sites and the conversion to open surgery was unnecessary. No intra-operative complications have been encountered, Table 1.

The post-operative mean time for patient ambulation was $9 \pm 1.8$ hours and oral fluid intake mean time was $3.5 \pm 1$ days. The hospital stay mean duration was $9.3 \pm 1.2$ days. Post-operative complications were one patient with leakage that has been conservatively managed, one patient has developed pneumonia, and a third case has been died at ICU because of pulmonary embolism.

Table 1. Perioperative outcomes.

\begin{tabular}{cc}
\hline Variable & Average or median (Range) \\
\hline Male/Female & $59(35-72)$ \\
Age (years) & $26.3(23-34)$ \\
The BMI & \\
Tumor location: & $15(15 / 27)$ \\
Pyloric region & $12(12 / 27)$ \\
Antral region & $8: 19$ \\
T1:T2 & \\
Reconstruction & $9 / 12 / 6$ \\
Pilroth-I/Bilroth-II/Roux en $Y$ & $3(\mathrm{SD} \pm 1.5)$ \\
Positive LNs & $12 / 7 / 8 / 0$
\end{tabular}

BMI: Body Mass Index; LNs: Lymph Nodes; N: lymph node status. 
The average number of obtained lymph nodes was $21.7 \pm 3.8$ lymph nodes. Free surgical margin has been achieved in all cases, Table 1.

The median number of reuse of the vascular sealing device was 3.8 times (3-5 times) and the estimated reduction in its cost in comparison to single use was $70 \%$ including re-sterilization cost. The median reuse of the vascular sealing device in laparoscopic distal gastrectomy compared to laparoscopic colectomy was 3.8 to 5 times respectively $(\mathrm{P}=0.05)$.

\section{Discussion}

The present study provides new evidences regarding the oncologic feasibility and surgical safety of incorporation of advanced laparoscopic surgical techniques for cancer in low to middle income countries.

In a previous study, we showed that laparoscopic colorectal surgery for malignant tumors in developing countries is potentially feasible and safe, and gave similar results for that of multicenter trials [22].

In this current study, we could successfully and safely perform laparoscopy assisted distal gastrectomy with D1 plus lymphadenectomy for distal gastric cancer guided by the oncologic surgical principles [19]. Although in this study we reused several times the single use hand piece of vascular sealing device for dissection and hemostasis; the advantages of minimal invasive surgery like précised dissection have been maintained. As shown in Table 1, our results have similarity to that of other studies for LADG [2] [15] [23] [24]. Moreover, no intra-operative complications have been found and only one case has been died in the post-operative period because of pulmonary embolism. This might be because of early ambulation and less postoperative pain. All these factors have contributed to the short post-operative hospital stay.

As we believe, the most important in cancer surgery is to respect the oncologic principals. In our series, the mean number of obtained lymph nodes was 21.7 $(\mathrm{SD} \pm 3.8)$ and all cases have negative surgical margin. Therefore our pathological results were similar to that of most previous reports [2] [15] [23] [24].

For safety and technical issues, in this study only D1 plus lymphadenectomy have been tried. We consider D2 lymphadenectomy as the standard technique and according to our improving skills for this advanced surgery; we have extended the lymphadenectomy to be $\mathrm{D} 2$ by the end of the study.

For the patients of gastric cancer in developing countries to get the benefits of the minimal invasive surgery, we believe that safe reuse of disposable laparoscopic instruments should be considered. The "single use" concept for expensive devices should be reviewed. Evidences for the possibility to sterilize the single use devices even with the contamination-challenge are present [25]. For economic issues we safely re-used vessel sealing bipolar devices several times which could be cost-effective [22] [26] [27]. The cost has been reduced by about 70\% that means 500 US Dollars at the time of the study which is a good financial benefit regarding Egypt economy. 
Our belief is that the surgeon has the responsibility of determining the functional integrity of any surgical instrument before its use [26].

The judicious choice of disposable and reusable instruments could provide the best possible tools for the surgeons in developing countries to perform laparoscopic procedures provided that patient safety and oncologic feasibility could be maintained [27] [28].

This study for our knowledge is the first study that evaluates the current practice of laparoscopic gastric resection for cancer in developing countries addressing the issue of reuse of disposable laparoscopic instruments. The results of this study have shown that we could perform safely and successfully laparoscopic distal gastrectomy with D1 plus LNs dissection for cancer in 27 cases.

In conclusion, Laparoscopic distal gastrectomy for cancer could be safe and feasible in developing countries and give similar results for that of developed countries. Safe reuse of single use expensive parts of some instruments for laparoscopy could help in utilization of these advanced surgeries in low to middle income countries. Long term follow up as well as comparative studies with open surgery are required.

\section{Funding Information}

No funding was received for this research.

\section{Conflicts of Interest}

No conflicts of interest or financial ties to be disclosed by the Authors.

\section{Ethical Approval}

All the procedures were adherent to the Helsinki Declaration of 1964 and later versions. Informed consent was obtained from all included patients in the study. The ethical committee at South Egypt Cancer Institute has approved this study.

\section{References}

[1] Kitano, S., Iso, Y., Moriyama, M. and Sugimachi, K. (1994) Laparoscopy-Assisted Billroth-I Gastrectomy. Surgical Laparoscopy \& Endoscopy, 4, 146-148.

[2] Lee, J.H., Han, H.S. and Lee, J.H. (2005) A Prospective Randomized Study Comparing Open vs Laparoscopy Assisted Distal Gastrectomy in Early Gastric Cancer: Early Results. Surgical Endoscopy, 19, 168-173.

https://doi.org/10.1007/s00464-004-8808-y

[3] Dulucq, J.L., Wintringer, P., Stabilini, C., Solinas, L., Perissat, J. and Mahajna, A. (2005) Laparoscopic and Open Gastric Resections for Malignant Lesions: A Prospective Comparative Study. Surgical Endoscopy, 19, 933-938. https://doi.org/10.1007/s00464-004-2172-9

[4] Zhao, Y., Yu, P., Hao, Y., Qian, F., Tang, B., Shi, Y., Luo, H. and Zhang, Y. (2011) Comparison of Outcomes for Laparoscopically Assisted and Open Radical Distal Gastrectomy with Lymphadenectomy for Advanced Gastric Cancer. Surgical Endoscopy, 25, 2960-2966. https://doi.org/10.1007/s00464-011-1652-y 
[5] Du, J., Zheng, J., Li, Y., Li, J., Ji, G., Dong, G., Yang, Z., Wang, W., Gao, Z. (2010) Laparoscopy-Assisted total Gastrectomy with Extended Lymph Node Resection for Advanced Gastric Cancer: Reports of 82 Cases. Hepatogastroenterology, 57, 1589-1594.

[6] Choy, I., Kitto, S., Adu-Aryee, N., Okrainec, A. (2013) Barriers to the Uptake of Laparoscopic Surgery in a Lower-Middle-Income Country. Surgical Endoscopy, 27, 4009-4015. https://doi.org/10.1007/s00464-013-3019-Z

[7] Baigrie, R.J. and Stupart, D. (2010) Introduction of Laparoscopic Colorectal Cancer Surgery in Developing Nations. British Journal of Surgery, 97, 625-627.

https://doi.org/10.1002/bjs.7090

[8] Ali, R., Khan, M.R., Pishori, T. and Tayeb, M. (2010) Laparoscopic Appendectomy for Acute Appendicitis: Is This a Feasible Option for Developing Countries? The Saudi Journal of Gastroenterology, 16, 25-29. https://doi.org/10.4103/1319-3767.58764

[9] Bal, S., Reddy, L.G., Parshad, R., Guleria, R. and Kashyap, L. (2003) Feasibility and Safety of Day Care Laparoscopic Cholecystectomy in a Developing Country. Postgraduate Medical Journal, 79, 284-288. https://doi.org/10.1136/pmj.79.931.284

[10] Gyedu, A., Fugar, S., Price, R. and Bingener, J. (2015) Patient Perceptions about Laparoscopy at Komfo Anokye Teaching Hospital, Ghana. Pan African Medical Journal, 20, 422. https://doi.org/10.11604/pamj.2015.20.422.6218

[11] Andreatta, P., Perosky, J., Klotz, J., Gamble, C., Ankobea, F., Danso, K. and Dalton, V. (2014) Pilot Study Outcomes from a Resource-Limited Setting for a Low-Cost Training Program for Laparoscopic Surgical Skills. International Journal of Gynecology \& Obstetrics, 125, 186-188. https://doi.org/10.1016/j.ijgo.2013.10.030

[12] Tanimura, S., Higashino, M., Fukunaga, Y., Takemura, M., Tanaka, Y., Fujiwara, Y. and Osugi, H. (2008) Laparoscopic Gastrectomy for Gastric Cancer: Experience with More than 600 Cases. Surgical Endoscopy, 22, 1161-1164. https://doi.org/10.1007/s00464-008-9786-2

[13] Lee, J.H., Yom, C.K. and Han, H.S. (2009) Comparison of Long-Term Outcomes of Laparoscopy-Assisted and Open Distal Gastrectomy for Early Gastric Cancer. Surgical Endoscopy, 23, 1759-1763. https://doi.org/10.1007/s00464-008-0198-0

[14] Munasinghe, A., Singh, B., Mahmoud, N., Joy, M., Chang, D.C., Penninckx, F. and Faiz, O. (2015) Reduced Perioperative Death Following Laparoscopic Colorectal Resection: Results of an International Observational Study. Surgical Endoscopy, 29, 3628-3639. https://doi.org/10.1007/s00464-015-4119-8

[15] Kim, Y.W., Baik, Y.H., Yun, Y.H., Nam, B.H., Kim, D.H., Choi, I.J. and Bae, J.M. (2008) Improved Quality of Life Outcomes after Laparoscopy-Assisted Distal Gastrectomy for Early Gastric Cancer: Results of a Prospective Randomized Clinical Trial. Annals of Surgery, 248, 721-727. https://doi.org/10.1097/SLA.0b013e318185e62e

[16] Kim, J.H., Jun, K.H. and Chin, H.M. (2017) Short-Term Surgical Outcomes of Laparoscopy-Assisted versus Totally Laparoscopic Billroth-II Gastrectomy for Gastric Cancer: A Matched-Cohort Study. BMC, 17, 45.

[17] Japanese Gastric Cancer Association (2011) Japanese Classification of Gastric Carcinoma: 3rd English Edition. Gastric Cancer, 14, 101-112.

[18] Sobin, L.H., Gospodarowicz, M.K. and Wittekind, C. (2009) TNM Classification of Malignant Tumours. Wiley, New York.

[19] Japanese Gastric Cancer Association (2011) Japanese Gastric Cancer Treatment Guidelines. Gastric Cancer, 14, 113-123. https://doi.org/10.1007/s10120-011-0042-4 
[20] Law, W.L., Lee, Y.M., Choi, H.K., Seto, C.L. and Ho, J.W. (2007) Impact of Laparoscopic Resection for Colorectal Cancer on Operative Outcomes and Survival. Annals of Surgery, 245, 1-7. https://doi.org/10.1097/01.sla.0000218170.41992.23

[21] Amin, A.T., Gabr, A. and Abbas, H. (2015) Laparoscopy Assisted Distal Gastrectomy for T1 to T2 Stage Gastric Cancer: A Pilot Study of Three Ports Technique. Up dates in Surgery, 67, 69-74. https://doi.org/10.1007/s13304-015-0279-2

[22] Amin, A.T., Ahmed, B.M. and Khallaf, S.M. (2015) Safety and Feasibility of Laparoscopic Colo-Rectal Surgery for Cancer at a Tertiary Center in a Developing Country: Egypt as an Example. Journal of the Egyptian National Cancer Institute, 27, 91-95. https://doi.org/10.1016/j.jnci.2015.03.005

[23] Kitano, S., Shiraishi, N., Fujii, K., Yasuda, K., Inomata, M. and Adachi, Y. (2002) A Randomized Controlled Trial Comparing Open vs. Laparoscopy-Assisted Distal Gastrectomy for the Treatment of Early Gastric Cancer: An Interim Report. Surgery, 131, S306-S311. https://doi.org/10.1067/msy.2002.120115

[24] Hayashi, H., Ochiai, T., Shimada, H. and Gunji, Y. (2005) Prospective Randomized Study of Open versus Laparoscopy-Assisted Distal Gastrectomy with Extraperigastric Lymph Node Dissection for Early Gastric Cancer. Surgical Endoscopy, 19, 1172-1176. https://doi.org/10.1007/s00464-004-8207-4

[25] Lopes, C.L., Graziano, K. and Pinto, T.J. (2011) Evaluation of Single-Use Reprocessed Laparoscopic Instrument Sterilization. Revista Latino-Americana De Enfermagem, 19, 370-377. https://doi.org/10.1590/S0104-11692011000200020

[26] Des Coteaux, J.G., Tye, L. and Poulin, E.C. (1996) Reuse of Disposable Laparoscopic Instruments: Cost Analysis. Canadian Journal of Surgery, 39, 133-139.

[27] Hailey, D., Jacobs, P.D., Ries, N.M. and Polisena, J. (2008) Reuse of Single Use Medical Devices in Canada: Clinical and Economic Outcomes, Legal and Ethical Issues, and Current Hospital Practice. International Journal of Technology Assessment in Health Care, 24, 430-436. https://doi.org/10.1017/S0266462308080562

[28] Larose, E. (2013) Legal Implications of Single-Use Medical Device Reprocessing. Healthcare Quarterly, 16, 48-52. https://doi.org/10.12927/hcq.2013.23499 